\title{
Effects of Different Diets on Population Growth of Cultured Cyclopoid Copepod, Mesocyclops leuckarti (Claus, 1857)
}

\author{
Chourpagar Atul R..$^{*}$ and Shaikh Rumana S. ${ }^{2}$ \\ 1Department of Zoology, Dadapatil Rajale Arts, Science and Commerce College, Adinathnagar-414505, Pathardi, Ahmednagar \\ (M.S.), India \\ 2Department of Zoology, Pemraj Sarda College, Ahmednagar-414001 (M.S.), India \\ ${ }^{*}$ Corresponding Author
}

Received: 24th March, 2021

Accepted: 28th April, 2021

Published online: $8^{\text {th }}$ May, 2021

https://doi.org/10.33745/ijzi.2021.v07i01.014

\begin{abstract}
In recent times aquaculture has become an increasingly important part of the world economy. Copepods play major roles in pond ecosystems serving as food for small fish, micro-predators on fish and other organisms, fish parasites, intermediate hosts of fish parasites and hosts and vectors of human diseases like cholera. Growth, reproduction and biochemical composition were analyzed for the copepod Mesocyclops leuckarti fed on four diets and their ratio like Bakers yeast (B), Baker's yeast+ Wheat flour (BW, 1:2), Bakers yeast + Chicken manure (BC, 1:2) and Bakers yeast + Chicken manure + Wheat flour (BCW, 1:2:2). The mean peak density of the copepod population was 569 individual/lit, for all four diets used. The highest was 587 individual/lit, on diet having combination of Bakers yeast, Chicken manure and Wheat flour (BCW). A small copepod Mesocyclops leuckarti tends to have a short life span and it was found to be important food items for fish larvae.
\end{abstract}

Keywords: Copepod, Population growth, Natural food, Cyclopoid copepoid

Citation: Chourpagar Atul R. and Shaikh Rumana S.: Effects of different diets on population growth of cultured cyclopoid copepod, Mesocyclops leuckarti (Claus, 1857). Intern. J. Zool. Invest. 7 (1): 176-181, 2021. https://doi.org/10.33745/ijzi.2021.v07i01.014

\section{Introduction}

Copepods are of great ecological significance and serve as a major food for numerous organism including fish and crustaceans (Kinne, 1977; Goswami, 1977; James and Thirunawookarase, 1986). Copepods have a wide range of size. Considering the various developmental stages in their life cycle, young naupli stages which are small about $50 \mu \mathrm{m}$ in size are of particular interest for early feed for fish larvae. They have a characteristics movement which induces feeding behaviour in young fish larvae. Copepoda are known for 
nutritive value, digestibility and cleaning effect in the rearing tank (Kahan, 1992). Mass cultivation of Acanthocyclops tonsa (Stottrup et al., 1986), Acanthocyclops insunsis (Ohno et al., 1990), Calanoids (Dharani, 1998) and Harpacticoids, Tisbe holothuria in a continuous culture system consists of closed copepod bioreactor connection to a continuous micro-algal cultivation system (Stottrup and Norskar, 1997). Copepods are widely distributed and best known group of voracious feeders. They feed on a variety of food items such as algae, pollen, detritus, bacteria, rotifers, crustaceans, chironomids mosquito larvae and even larval fish (Fryer' 1957; Manakovl 1976; Marten, 1990) therefore they occupy three of the four major trophic positions in the food chain detritivorus, herbivores and carnivores. The calanoids and cyclopoid species are mostly omnivorous while harpacticoids are mostly detritus feeder.

Copepods make use of their chemo- and mechanoreceptors to locate and ingest its pry. Calanoids appear to use both chemoreceptors, while cyclopoids depend more on mechanoreceptors than chemoreceptors in detaching the prey (Williamson, 1991). Due to the importance of the copepods as primary and secondary consumers in the aquatic food and feeding habitats, this group is intensively investigated for both animals from wild and under laboratory conditions. Important contributions on the aspect are by Fryer (1957), Gliuriz (1969), Smyly (1961), Selander et al. (2019), Soler-Jiménez et al. (2019) and Altaff (2020).

\section{Materials and Methods}

Zooplankton samples were collected from freshwater lake at Mombatta Lake at
Daulatabad valley around Aurangabad, India. Live zooplankton samples were transported to the laboratory in polythene bag within an hour. Different groups of copepods were separated under binocular steriozoom dissection microscope using a fine brush and needle. Mesocyclops leuckarti were identified on the basis of Edmondson (1959), Van de Veldle (1984), Lim and Fernando (1985), Maas (1994), Reddy (1994), Dussart and Defaye (1995) and Altaf (2004). They were maintained in pretreated water (tap water double filtered with 42 um bolten silk and allowed to settle in large aquarium at room temperature for $48 \mathrm{~h}$ and aerated for $12-24 \mathrm{~h}$ prior to use). They were fed with Baker's yeast, wheat flour and chicken manure on alternate days. Multiple generation of Mesocyclops leuckarti were reared in the laboratory which have been used for various experimental studies.

The Copepoda were maintained as stock cultures in the laboratory. Each new culture was started by adding 10 adults Mesocyclops leuckarti. The copepods were fed a daily ration of four different diets (i) Baker's yeast (B) alone, (ii) Baker's yeast + wheat flour (BW, $1: 2$ ), (iii) Baker's yeast + chicken manure (BC, 1:2) and (iv) A diet containing all three components Baker's yeast + chicken manure + wheat flour (BCW, 1:2:2).

\section{Population growth:}

Ten ovigerous females (40 eggs/female) and five adult males were selected to begin each growth experiment. Experimental copepods were kept in 4 glass bottles (beaker) under room temperature and light (300 lux), with gentle aeration. During the daily transfer to clean bottles containing fresh food, copepods were placed on cavity slides and measured for 
total body length (from the anterior end of the head to the tip of the caudal ramus). The number of offspring per female mean fecundity (number of nauplii/female), longevity (days) and post embryonic development period (hours) were recorded and all copepods were followed until natural death for each experiment. There were four replicates.

\section{Results}

\section{Population Growth:}

The three phases of population development identified for Mesocyclops leuckarti raised on four different diets (i) Bakers yeast [B] alone, (ii) Bakers yeast + wheat flour [BW, 1:2], (iii) Bakers yeast + chicken manure [BC, 1:2] and (iv) A diet containing all three components Baker's yeast + chicken manure + wheat flour [BCW, 1:2:2] are shown in Figure 1. The first phase of population growth/initial growth (IG) was the shortest about 3 days. The fastest growth rate in this phase was attained on diet Baker's yeast. The second phase Growth (G) was the longest, from day 4 to 16 . In this phase also, diet B yields the highest growth rates. The last or stabilization (s) phase was the period after which the Mesocyclops leuckarti population tend to diminish. During this period the highest growth rates were achieved on diets Bakers yeast and Bakers yeast + chicken manure. Maximum population density peaks for Mesocyclops leuckarti were similar for all diets. Varying from 533 ind. /liter (Baker's yeast) to 587 ind. /liter (Bakers yeast + chicken manure + wheat flour). The peak population density reached on days 14 and 16 for diets (B) and (BW), respectively and on day 20 for BCW diets (Table 1). Length of the copepods varied from 1800 to $1900 \mu \mathrm{m}$ for females, 1580 to $1670 \mu \mathrm{m}$ for males, from 470 to $172 \mu \mathrm{m}$ for nauplii. For female copepodids and naupliithe best diet was Baker's yeast (B), whereas for males it was Baker's yeast + wheat flour (BW). The mean duration of embryonic and post- embryonic development, together with other life cycle characteristics are shown in Table 2. There were no significant differences in period of embryonic development, which varied from 23.89 to $24.44 \mathrm{~h}$ among diets. There were some differences in post-embryonic development of Mesocyclops leuckarti which had the longest development time 8.57 days, when fed diet BC; whereas the BW diet resulted in slightly shorter development time of approximately 7.87 days.

Table 1: Maximum population density peaks and optimum culture times for the copepod Mesocyclops leuckarti maintained on different diets: Baker's yeast (B), Baker's yeast + wheat flour (BW, 1:2), Baker's yeast+ chicken manure (BC, 1:2) and Baker's yeast + chicken manure+ wheat flour (BCW, 1:2:2)

\begin{tabular}{|l|c|c|}
\hline \multicolumn{1}{|c|}{ Diets } & $\begin{array}{c}\text { Maximum } \\
\text { Peak } \\
\text { (ind./lit.) }\end{array}$ & $\begin{array}{l}\text { Optimum } \\
\text { culture } \\
\text { (Day) }\end{array}$ \\
\hline B & 543 & 14.7 \\
\hline BW (1:2) & 563 & 16.1 \\
\hline BC (1:2) & 585 & 21.5 \\
\hline BCW (1:2:2) & 587 & 20.4 \\
\hline $\begin{array}{l}\text { Total } \\
\text { population }\end{array}$ & 569.5 \\
\hline
\end{tabular}

In general, the mean number of nauplii per female was 51.54 for diet BW. Total fecundity (total number of nauplii produced over a female's life span) was similar for diets BC and BCW, with $48.85 \pm 3.47$ and $48.46 \pm 3.94$ nauplii, respectively. Copepods eating only algae (diet B) showed slightly lower total fecundity with 44.81 \pm 3.66 nauplii. 


\section{Population Growth Phases}

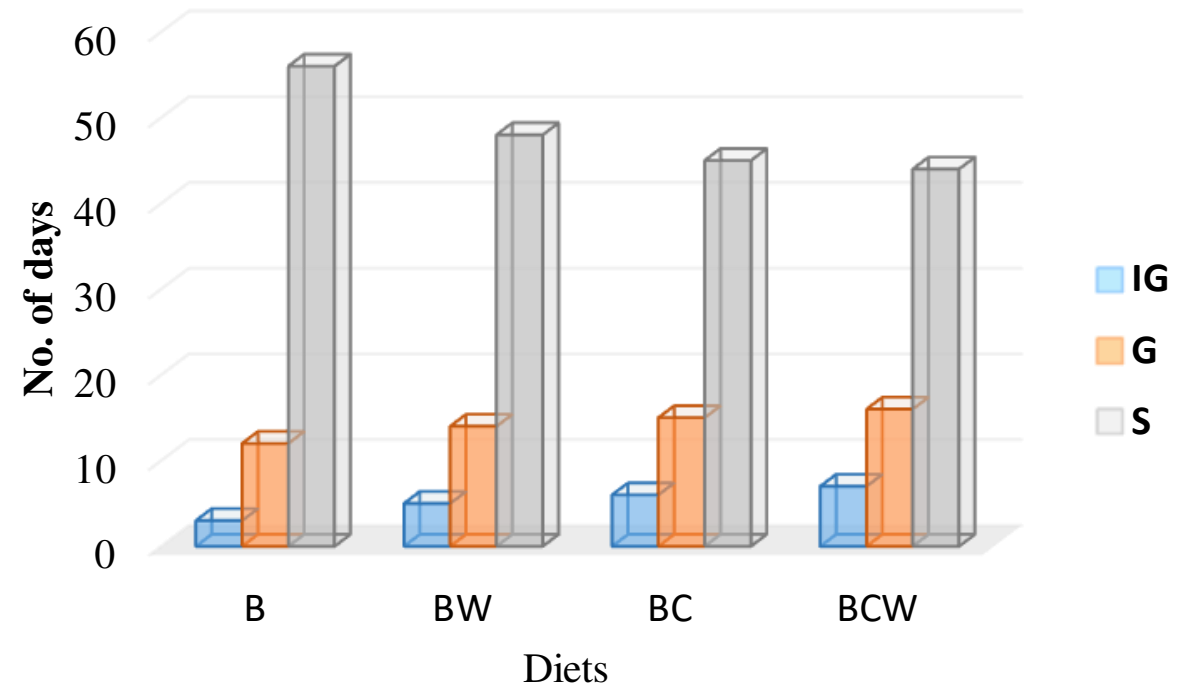

Fig.1: Population growth phase (Initial growth, Growth, Stabilization).of four different diets of (B), (BW), $(\mathrm{BC})$ and $(\mathrm{BCW})$

Table 2: Life history parameters of the copepod Mesocyclops leuckarti maintained on diets of Baker's yeast (B), Baker's yeast + wheat flour (BW, 1:2), Baker's yeast+ chicken manure (BC, 1:2) and Baker's yeast + chicken manure+ wheat flour (BCW, 1:2:2)

\begin{tabular}{|c|l|c|c|c|c|}
\hline $\begin{array}{l}\text { S. } \\
\text { No. }\end{array}$ & Parameters & \multicolumn{3}{|c|}{ B Diets } \\
\hline 1. & $\begin{array}{l}\text { Mean Embryonic } \\
\text { Development Time (h) }\end{array}$ & $24.16 \pm 2.55$ & $24.44 \pm 2.76$ & $24.44 \pm 2.76$ & $23.89 \pm 2.78$ \\
\hline 2. & $\begin{array}{l}\text { Mean post Embryonic } \\
\text { Development Time (Days) }\end{array}$ & $8.17 \pm 0.27$ & $7.87 \pm 0.26$ & $8.57 \pm 0.27$ & $8.51 \pm 0.27$ \\
\hline 3. & $\begin{array}{l}\text { Mean Fecundity } \\
\text { (Nauplii/Female) }\end{array}$ & $44.81 \pm 3.66$ & $51.54 \pm 4.05$ & $48.85 \pm 3.47$ & $48.46 \pm 3.94$ \\
\hline 4. & $\begin{array}{l}\text { Mean Number of } \\
\text { Offspring/Female }\end{array}$ & $4.00 \pm 0.77$ & $4.00 \pm 0.77$ & $3.46 \pm 0.77$ & $3.62 \pm 0.70$ \\
\hline 5. & $\begin{array}{l}\text { Longevity (Days) } \\
6 .\end{array}$ & 53 & 50 & 46 & 44 \\
\hline
\end{tabular}

There were no significant differences among diets in the number of offspring per female. Diets B and BW resulted in slightly higher numbers of offspring per female (Table 2 ). There were differences in longevity among copepods on the four diets (Table 2). Animals on the $\mathrm{BC}$ and $\mathrm{BCW}$ diets died much sooner than animals on the other diets and animals on BCW had significantly shorter life spans than animals on BC. There was an inverse relationship between temperature and longevity; mean longevity was 44 days at $26 \mathrm{C}$ 
and 46 days at $25 \mathrm{C}$. At $25 \mathrm{C}$, copepods on diet $B$ lived longer than those on diets $B C$ and BCW.

\section{Discussion}

Present study of copepods life cycle culture methods and their use as natural food for fish larvae might help develop more accurate techniques for large scale culture of copepods, thus making feasible their use as a high quality and easily digestible food. All the diets used in the present study were efficient. Copepods fed the (BCW, 1:2:2) diet reached the highest density. The mean peak density of the culture was almost 569 ind. /liter (the highest was 587 ind./liter on the diet having combination of Bakers yeast + chicken manure + wheat flour (BCW, 1:2:2).

The culture procedure used in the present investigation differed from others described in the literature in that cultures were started using adults rather than eggs or nauplii. According to Schipp et al. (1999), eggs should not be used because the rinsing process damages their setae, preventing normal molting and resulting in their death within $24 \mathrm{~h}$.

Schipp et al. (1999) observed that species of Acartia have a generation time of 5-7 days, depending on water temperature. Their preliminary trials indicated that an 8-day culture cycle was required to maximize copepod productivity. Hardy and Duncan (1994) reported that temperature was the main factor controlling the embryonic development time of the Cladocera Daphnia gessneri reared on higher food levels $0.03 \mathrm{mg}$ c/lit.), with mean values of 24-31 h at $32 \mathrm{C}$ and post-embryonic development time of 7 days.
The mean embryonic and post-embryonic development times observed for the cultures of Mesocyclops leuckarti were slightly higher than those observed by Hardy and Duncan (1984). However, the copepods lived longer than the Cladocerans, with 3 developmental stages (nauplii, copepodid and adult) and had greater mortality during molting. Noticeable differences in longevity were also found. Smaller copepods tend to have shorter life spans overall. Larger individuals of Mesocyclops leuckarti lived longest on diet $\mathrm{B}$, whereas smaller individuals had shorter life spans on the other diets. According to Lynch (1980), the smaller species tend to have shorter life spans. Rahmati et al. (2020) studied the potential of using specifically dry microalgae to improve the nutritional composition in copepods as a suitable supplementary live food for freshwater fish larvae.

\section{References}

Altaf, K. (2004) A manual of zooplankton. University Grants Commission, New Delhi.

Altaff K. (2020) Feeding and reproductive biology of two potential calanoid copepod species of pseudodiaptomus for mass culture. Intern J Zool Invest. 6: 246-259.

Dharani G. (1998) Reproductive biology and culture of the freshwater plankton Sinodiaptomus (Rhinediaptomus) indicus (Kiefer) (Calanoida: Copepoda). Ph.D. Thesis, University of Madras.

Dussart BH and Defaye D. (1995) Copepoda: Introduction to the Copepoda. SPB Academic Publishing, Amsterdam, Netherland.

Edmondson WT. (1959) Freshwater Biology. 2nd Ed. John Wily and Sons, New York, U.S.A.

Fryer G. (1957) The feeding mechanism of some freshwater cyclopoid copepods. Proc Zool Soc Lond. 129: 1-25. 
Gliuriz ZM. (1969) Studies on the feeding of pelagic zooplanktons in lakes with varying trophy. Ekol Pol. 17: 663-707.

Goswami SC. (1977) Laboratory culture of Harpacticoids copepod, Laophonte setosa (Boeck). Proc Symp Warm Water Zoopl Spl Pub. 563-570. http://drs.nio.org/drs/handle/2264/5422.

Hardy ER and Duncan A. (1994) Food concentration and temperature effects on life cycle characteristics of tropical Cladocera (Daphnia gessneri Herbst, Diaphanosoma sarsi Richard, Moina reticulata (Daday): I. Development time. Acta Amazonica 24: 119-134.

James CM and Thirunawookarase AR. (1986) Selectivity and food ration of fry of milk fish Chanos chanos (Forskal) under laboratory conditions. Proc Symp Coast Aqut. 6: 1286-1294.

Kahan D. (1992) Mass cultivation of food organisms in hatcheries problems and proposed solutions. Proc Symp Coast Aquacult. 1: 314-320.

Kinne O. (1977) Cultivation of animals. Research cultivation. In: Marine ecology. (ed.) Kinne O. WileyInterscience, Chichester 3: 691-709.

Lim RP and Fernando CH. (1985) A review of Malaysian freshwater Copepoda with notes on new records and little known species. Hydrobiologia 128: 71-89.

Lynch M. (1980) The evolution of cladoceran life histories. Q Rev Biol. 55: 23-42.

Mass S. (1994) Introduction to the Copepod. International Training Course, Lake Zooplankton: a tool in lake management. University of Ghent. Belgium, 1-128.

Manakov AU. (1979) Review of studies on feeding of aquatic invertebrates conducted at the Institute of Biology of Inland Water, Academy of Sciences, USSR. J Fish Res Bd Can. 29:363-383.

Marten CG. (1990) Elimination of Acedes albopictus from the pile by introducing Macrocyclops albidus (Copepodae). J Am Mosq Cont Assoc. 6: 689-693.

Ohno A, Takahashi T and Taki Y. (1990) Dynamics of exploited populations of the calanoid copepod, Acartia tsuensis. Aquacult. 84: 27-39.
Rahmati R, Esmaeili Fereidouni A., Rouhi A. and Agh N. (2020) Effects of different diets on population growth and fatty acids composition in cyclopoid copepod, Acanthocyclops trajani(Mirabdullayev and Defaye, 2002): A potential supplementary live food for freshwater fish larvae. Iranian J Fisheries Sci. 19: 1447-1462.

Reddy YR. (1994) Copepoda: Calanoda: Diaptomidae: Guide to the identification of the microinvertebrates of the continental waters of the world. 5, SPB Publishers, The Hague, Netherland.

Schipp GR, Bosmans JMP and Marshall AJ. (1999) A method for the hatchery culture of tropical calanoid copepods, Acartia spp. Aquacult. 174: 81-88.

Selander E, Berglund EC, Engström P, Berggren F, Eklund J, Harðardóttir S, Lundholm N, Grebner W and Andersson MX. (2019) Copepods drive largescale trait-mediated effects in marine plankton. Sci Adv. 5: eaat5096. DOI: 10.1126/sciadv.aat5096.

Smyly WJP. (1961) The life-cycle of the freshwater copepod Cyclops leuckarti Claus in Esthwaite water. J Anim Ecol. 30: 153-169.

Soler-Jiménez LC, Morales-Serna FN, Aguirre-Macedo ML, McLaughlin JP, Jaramillo AG, Shaw JC, James AK, Hechinger RF, Kuris AM, Lafferty KD and VidalMartínez VM. (2019) Parasitic copepods (Crustacea, Hexanauplia) on fishes from the lagoon flats of Palmyra Atoll, Central Pacific. ZooKeys 833: 85-106.

Stottrup JG, Richardsen K, Kirkegaard E and Pihl NJ. (1986) The cultivation of Acartia tonsa (Dana) for use as live food source of Marine Fish Larvae. Aquacult.. 52: 87-96.

Stottrup JG and Norsker NH. (1997) Production and use of Copepods in marine fish larviculture. Aquacult. 155: $231-247$.

Van de Veldle I. (1984) Revision of the African species of the genus Mesocyclops Sars 1914 (Copepoda: Cyclopoida). Hydrobiol. 109: 3-66.

Williamson CE. (1991) Copepoda. Ecology and classification of North American freshwater invertebrates. Academic Press, Inc. Pp 787-822. 